\title{
BREVE SEMBLANZA DE EUGENIA
}

\section{Clara $M^{a}$ Thomas de Antonio}

Como profesora más veterana del Área de Estudios Árabes e Islámicos de la Universidad de Sevilla al jubilarse la Dra. Gálvez, me ha correspondido el honor de representar a mis compañeros en este acto de homenaje, en el que queremos demostrarle nuestro reconocimiento a su labor docente e investigadora, siempre volcada en el campo del arabismo. Pero, al haber compartido con ella casi tres décadas de proyectos e ilusiones -primero en la antigua Facultad de Filosofía y Letras y luego en la actual Facultad de Filología-, será inevitable que también se vayan entremezclando en mis palabras experiencias y sentimientos relacionados con su faceta humana. Por ello, me voy a permitir sustituir el protocolario "Dra. Gálvez" por el más personal "Eugenia", ya que es así como nos hemos tratado a diario durante tanto tiempo.

Eugenia, nacida en Málaga y muy ligada también a tierras granadinas -recuerdo bien nuestras charlas sobre esa tierra, y en especial sobre un entrañable pueblecito llamado Pitres-, se licenció en Filología Semítica por la Universidad Complutense de Madrid hace cuatro décadas.

Concluidos sus estudios, partió llena de ilusión hacia Egipto en 1959 para hacerse cargo de la subdirección del Centro Cultural Hispánico de Alejandría. Esa estancia en Egipto, que repetiría años más tarde, probablemente orientó su vocación hacia el campo de la literatura egipcia, al que tantos esfuerzos ha dedicado.

Ya desde antes de su regreso a Madrid en 1961 fue colaboradora en el Instituto HispanoÁrabe de Cultura, que durante esos años desplegó una intensa labor cultural, en la que Eugenia participó muy activamente de 1960 a 1964.

En este último año se incorporó a la docencia como profesora de la Universidad Complutense. Y fue entonces cuando la conocí, y cuando me puso en contacto por primera vez con la literatura árabe contemporánea, a la que ahora dedico la mayor parte de mis trabajos: con ella nos deleitamos en el estudio de El canto de la muerte, una estupenda obra de teatro del egipcio Tawfĩ al-Hakīm; años más tarde y ya en Sevilla, Eugenia propondría a nuestros alumnos la representación de dicha obra, en la espléndida versión de Pedro Martínez Montávez, y los dirigiría con auténtica maestría.

En 1970 los avatares de la vida volvieron a reunirnos. Cada una de nosotras, por distintos motivos, acabábamos de aterrizar en esta hermosa ciudad y deseábamos trabajar como arabistas. Ese mismo año Pedro Martínez Montávez había tomado posesión de la Cátedra de Árabe de la Universidad de Sevilla, por lo que comenzó a constituir el que sería el primer Departamento de Árabe de nuestra Facultad... Y así comenzamos a trabajar juntas, compartiendo esfuerzos y proyectos, hasta la actualidad, junto a profesores veteranos -Ramón 
Mendoza, Gamāl 'Abd al-Karīm-, profesores que poco a poco se fueron incorporando al Departamento -José Vázquez, Braulio Justel, Rafael Valencia, Fátima Roldán, Pedro Cano, Julia $\mathbf{M}^{\mathrm{a}}$ Carabaza, $\mathbf{M}^{\mathrm{a}}$ Dolores López Enamorado, Juan A. Pacheco, Ingrid Bejarano, Emilio González Ferrín e Ildefonso Garijo- y sucesivas promociones de estudiantes.

En 1973 Eugenia defendió su Tesis Doctoral, titulada El cuento en la literatura árabe contemporánea. Una tipología social del Egipto de entreguerras, según la narrativa breve de Mahmüd Taymūr, dirigida por el recordado Elías Terés Sádaba, en la Universidad Complutense. Parte de esta obra, pionera en su planteamiento, sería editada en 1974 por el Servicio de Publicaciones de la Universidad de Sevilla, y ya cuenta con una segunda edición, como bien saben los estudiosos de la literatura egipcia contemporánea y como han podido comprobar las distintas promociones de alumnos que han pasado por nuestras aulas.

Superando circunstancias de todo tipo, Eugenia obtuvo en 1985 su plaza de Profesora Titular en la Universidad de Sevilla. También ese mismo año comenzó a impartirse por primera vez en nuestra Facultad la Especialidad de Filología Árabe, en cuyo logro tuvo Eugenia un destacado papel.

En 1988, tras haber dirigido la actividad docente e investigadora del Área, fue nombrada Directora del Departamento de Lengua y Literatura Árabes. Y cuando cambió la organización de los departamentos universitarios, en 1990, fue elegida Secretaria del Dpto. de Filologías Integradas, especie de cajón de sastre en el que quedó incluida el Área de Estudios Árabes e Islámicos, cargo en el que permaneció hasta 1993.

En el curso 1997-98 se empezó a impatir el nuevo Plan de Estudios de la Especialidad de Filología Árabe, en cuya elaboración Eugenia ostentó nuestra representación en la Comisión de la Facultad de Filología (1994-95), defendiendo contra viento y marea los intereses de la Especialidad. Ése es el plan que estamos impartiendo en estos momentos. Y, gracias a su implantación, el Área ha seguido creciendo, al incorporarse nuevos profesores -Pablo Beneito, $\mathrm{M}^{\mathrm{a}}$ del Carmen Romero y Ana $\mathrm{M}^{\mathrm{a}}$ Cabo- y una becaria de investigación - $\mathbf{M}^{\mathrm{a}}$ del Carmen Carriazo- a sus actividades.

¡No es magra cosecha la que hemos recogido del esfuerzo de Eugenia... ! A lo largo de los últimos 33 años ha impartido docencia de muy diversas materias propias de nuestra Licenciatura y numerosos cursos de Doctorado a partir de la implantación de la Especialidad, del mismo modo que ha dirigido diversos Trabajos de Investigación, Tesis de Licenciatura y Tesis Doctorales, imposibles de recoger aquí. En todo caso, somos muchos -profesores y alumnos- los que nos hemos beneficiado de su actividad académica.

Entre los diversos cursos y seminarios que ha dirigido en estas décadas en nuestra Facultad cabe destacar el "Seminario de Septiembre" de 1990, en el que impartió la conferencia inaugural; las "I y II Jornadas de Cine árabe" que se celebraron en los años 1995 y 1996, patrocinadas por el Vicerrectorado de Extensión Universitaria; o las "Jornadas de Árabe 
Moderno y Dialectal" celebradas en 1996, 1997 y 1998, también patrocinadas por el Vicerrectorado de Extensión Universitaria...

De sus estancias en centros extranjeros, sobresalen, además de la mencionada de Alejandría (1959-61), la realizada en 1990 en Dār al-Kutub (El Cairo), con una Beca del Instituto de Cooperación con el Mundo Árabe (Madrid), investigando sobre "La búsqueda de la identidad egipcia"; o la de 1995 en la Accademia dei Lincei (Roma), investigando sobre "Roger I de Sicilia".

A todas estas actividades hay que añadir su intensa actividad investigadora, que inició, nada más finalizar los estudios de Filología Semítica, en el Instituto Hispano-Árabe de Cultura de Madrid, prosiguiéndola en la Universidad Complutense y posteriormente en la Universidad de Sevilla. Sus principales líneas de investigación, a la que ha dedicado gran parte de sus esfuerzos a lo largo de su dilatada trayectoria, han sido la literatura árabe contemporánea, con especial incidencia en la egipcia, variados aspectos del Occidente de Al-Andalus y otros temas misceláneos, trabajos en los que destacan tanto sus aportaciones como el rico y expresivo lenguaje con que las ha realizado. Además, en 1990 fue nombrada miembro del "Equipo para la Elaboración del Corpus Nacional de Epigrafía Árabe", del Ministerio de Cultura. Y desde principios de los 90 es miembro del grupo de investigación "Ixbilia" de la Junta de Andalucía, integrado por varios miembros de nuestro Departamento.

Parte de su actividad investigadora se ha reflejado en sus numerosas intervenciones en Congresos, Jornadas y Encuentros, y necesitaríamos mucho espacio para citar aquellos en los que ha presentado comunicaciones y ponencias, en los que ha presidido sesiones o en los que ha ostentado la representación española: Tetuán (1988), Zaragoza (1988), Marrakech (1989), Almería (1990), Granada (1990), Assila (1990), Tetuán (1991), Sevilla (1991, 1992, 1993), Roma (1993), Granada (1994), El Escorial (1995), Alcalá de Henares (1997), etc.

Otra parte de esa actividad investigadora ha visto la luz en un buen número de publicaciones. Ya en 1965 se editaron sus traducciones de relatos de autores como el iraquí "Abd Allāh al-Niŷāzī ("El hombre y la orgullosa"), el marroquí Ahmad Mustafà al-Haršānī ("Una tenue luz"), o los tunecinos Naŷiya Tāmir ("La voz de los ruiseñores") e Ibn al-Wāḥa ("Heroismo"). En 1978 publicó la traducción de relatos de narradores tunecinos, como el mencionado Ibn al-Wāha -'Abd all-Rahmmān 'Ammār-("La compasión prohibida"), Muhammad Raššād al-Hamzāwī ("Tarnano" y "Budūda ha muerto") o Bašīr Jurayyif ("Barg al-Layl"). En 1981 vio la luz su traducción de "El farol de la calle tortuosa", del marroquí Mubārak Drīīi. Y en 1966 participó con otros miembros del Seminario de Literatura Árabe Contemporánea, del Instituto Hispano-Árabe de Cultura, en recopilar su Contribución para una bibliografía de la literatura árabe contemporánea.

Pero, a partir de su estancia en Egipto, dedicó la mayoría de sus trabajos a la moderna literatura egipcia. Se asoma a este campo en 1963 traduciendo una obrita de teatro del gran dramaturgo Tawfíq al-Hakīm ("La casa de las hormigas"), y en 1965 con su versión de un relato del pionero Muhammad Taymūr ("El silbato de la fiesta"). Pero será su hermano, Maḥmūd Taymūr -padre del relato árabe moderno, del que ya había publicado un primer relato 
en 1965 ("Abū cArab")-, quien la cautive y la incite a sumergirse en el estudio de su obra para abordarla en profundidad. Sobre él realiza su Tesis Doctoral, ya mencionada, y en él se centrarán varias de sus publicaciones posteriores: El Cairo de Mahmǜ Taymūr. Personajes Literarios (1974), "Aspectos del campesinado egipcio en los cuentos de Mahmuūd Taymūr" (1974) o Cuentos egipcios de Mahmüd Taymür (1976).

Más tarde, tras una etapa investigando sobre otros temas, vuelve a dedicarse a la literatura egipcia cuando el extraordinario narrador egipcio Naŷî̉ Maḥūẓ recibe el Premio Nobel de Literatura en 1988, abordando la traducción de su magnífica Trilogía (Entre dos palacios, 1989 y 1999; Palacio del deseo, 1990 y 1999; La azucarera, 1991 y 2000) con un equipo en el que estábamos varios miembros del Área y otros arabistas: R. Gil, C. Gómez Camarero, Ma D. López Enamorado, R. Monclova, F. Ramos, C. $\mathbf{M}^{\mathrm{a}}$ Thomas y R. Valencia. También prologará en 1998 Análisis de la temporalidad en la Trilogía de Naŷỉ Mahfǘ, de $\mathrm{M}^{\mathfrak{a}}$ Dolores López Enamorado, cuya Tesis Doctoral sobre este autor había dirigido. Además ha publicado artículos sobre otros aspectos de Egipto, como "Vida cotidiana en una aldea egipcia" (1984), "La narrativa egipcia" (1989) y "El faraonismo como leit motiv en la literatura egipcia" (1993). Y más recientemente ha formado un equipo de estudiantes para editar Las noches más baratas. Cuentos cortos (1996), de otro famoso narrador egipcio, Yūsuf Idrīs.

Pero su dedicación a la literatura árabe y egipcia contemporánea no le impidió trabajar en otros temas. Al inicio de su carrera publicó "Consideraciones sobre la inscripción de un tintero califal de la iglesia de Corberes (Rosellón)" (1963). Y desde su llegada a Sevilla, Eugenia volvió a ese campo de investigación y lo amplió, para penetrar -sola o en colaboración con otros investigadores- en diversos temas relacionados con el Occidente de al-Andalus: la numismática -"Una propuesta para la sistematización de la transcripción de textos y nombres árabes en trabajos de numismática andalusí", 1982; "Un tesorillo de dirhemes almohades del Museo Arqueológico de Sevilla", con D. Oliva y R. Valencia, 1983; "Aportación al estudio de la cora de Firrix: El tesorillo almohade de El Pedroso (Sevilla)", con R. Valencia, 1988-; la epigrafía -"Aclaración sobre la inscripción fundacional de una mezquita, hallada en Arcos de la Frontera", 1984; "Fondos epigráficos del Museo Arqueológico de Sevilla", con D. Oliva y R. Valencia, 1985; "Fondos epigráficos árabes del Museo Arqueológico de Sevilla: Brocales de pozo", con D. Oliva y R. Valencia, 1987-; su historia y patrimonio -"De nuevo sobre Talyâta", 1978; "Chorographia Hispalense", 1982; "Sevilla entre dos mundos (711-1492): De África a América", con D. Oliva y R. Valencia, 1983; "Las artes de los pueblos del Islam", con D. Oliva y R. Valencia, 1984; "Los manuscritos árabes del Archivo de Medinaceli", 1985; "El Guadalquivir musulmán", 1985; "Fragmento de ŷarida del Archivo Ducal de Medinaceli de Sevilla", 1990; "Las raíces de la casa de Mañara", con J. A. Gallego, D. Oliva y R. Valencia, 1993; "Noticias sobre los manuscritos árabes del Archivo Ducal de Medinaceli", 1995; "Almanzor, un héroe andalusí", 1996-97-; o las invasiones africanas -"Movimientos en el estrecho de las dinastías africanas", con F. Roldán, 1988-.

Y aún le quedó tiempo para trabajar en campos como el africanismo español -"La guerra de África (1909) en la prensa sevillana", con M² D. López Enamorado, 1993-, el Corán -"Los Amtâl en el Corán", 1995- o la ópera -"Influencia Oriental en la Ópera Alemana", 1997-. Por 
otro lado, su admiración hacia el ilustre arabista D. Emilio García Gómez la llevaría a glosar su figura en "Don Emilio García Gómez y la traducción literaria" (1997) y "Don Emilio García Gómez, un hombre universal" (1998).

Éste es, a grandes rasgos, el intenso curriculum docente, investigador y humano de la profesora Gálvez, del que sólo he podido resaltar los aspectos más relevantes y a la vez más cercanos a nuestras vivencias. Han sido muchos años de incesante labor, de estrecha relación con discípulos y compañeros, que sin duda han dejado su huella en ellos.

Eugenia, ahora que has culminado esta etapa, puedes mirar atrás y sentirte satisfecha por la senda recorrida. Siempre he admirado -y hemos admirado- tu valentía y entereza para superar dolencias y avatares y para afrontar la enorme actividad que has desplegado. Seguro que seguirás en la brecha, con el mismo tesón, con la misma vitalidad y entereza, abriendo nuevos caminos.

Por todo ello quiero -y queremos- demostrarte nuestro reconocimiento y, a la vez, desearte una jubilación "jubilosa", en la que puedas disfrutar más de los tuyos y en la que continúes participando, ya a tu ritmo y sin tantas fatigas, en esta tarea colectiva del arabismo al que tanto has brindado. Recibe, pues, nuestra felicitación y nuestro abrazo colectivo. ¡ Y no olvides que éste siempre será tu Departamento!

Sevilla, 24 de Octubre de 1998

Hay otros aspectos de la trayectoria de Eugenia de los que podrían hablar con más propiedad personas que han compartido con ella durante estas décadas numerosas vivencias, humanas y profesionales. Muchas son esas personas, que de un modo u otro han querido sumarse a este merecido homenaje. Pero pensamos que todas ellas podían estar representadas por las cuatro que intervendrán a continuación. Y lo van a hacer siguiendo el orden cronológico en que trabaron relación con Eugenia. Por ello damos la palabra a:

- El Dr. Pedro Martínez Montávez, Catedrático de Lengua y Literatura Árabes en el Departamento de Estudios Árabes e Islámicos de la Facultad de Filosofía y Letras de la Universidad Autónoma de Madrid y ex-Rector de dicha Universidad.

- La Dra. Ma Jesús Viguera Molins, Catedrática de Estudios Árabes e Islámicos en la Facultad de Filología de la Universidad Complutense de Madrid.

- La Dra. Carmen Ruiz Bravo-Villasante, Profesora Titular -hoy catedrática- del Departamento de Estudios Árabes e Islámicos de la Facultad de Filosofía y Letras de la Universidad Autónoma de Madrid.

- Y el Dr. Emilio de Santiago, Profesor Titular del Departamento de Filología Semítica de la Facultad de Filosofía y Letras de la Universidad de Granada. 
